\title{
KONSTRIBUSI KEBIJAKAN PENINGKATAN JUMLAH SISWA SMK TERHADAP PEMBANGUNAN EKONOMI INDONESIA
}

\author{
Slamet PH \\ Fakultas Teknik Universitas Negeri Yogyakarta \\ email: slametph@yahoo.com
}

\begin{abstract}
Abstrak: Untuk mendukung pembangunan ekonomi, Kementerian Pendidikan Nasional membuat kebijakan yang signifikan tentang proporsi jumlah siswa SMA dan SMK dari 57,85\%:42,15\% pada tahun 2007 dan menjadi 30\%:70\% pada tahun 2014. Kebijakan tersebut diharapkan mendukung pertumbuhan ekonomi dan mengurangi pengangguran. Kebijakan tersebut hanya didasarkan atas asumsi dan bukan data. Tujuan penelitian ini untuk: (1) menemukan proporsi jumlah siswa SMA dibanding siswa SMK tahun 2007 dan tahun 2014; (2) menemukan besarnya dukungan perbanyakan jumlah siswa SMK terhadap pertumbuhan ekonomi; (3) menemukan kontribusi ekspansi jumlah siswa SMK terhadap pengurangan pengangguran; (4) menyusun konsep proporsi jumlah siswa SMA dan SMK yang selaras dengan kebutuhan pembangunan ekonomi. Metode penelitian yang digunakan adalah diskriptif kuantitatif. Hasil penelitian ditemukan bahwa: (1) proporsi jumlah siswa SMA:SMK pada tahun 2014 adalah 51\%:49\%; (2) peningkatan jumlah siswa SMK tidak mendukung pertumbuhan ekonomi; (3) peningkatan jumlah siswa SMK menyebabkan tingkat pengangguran lulusan SMK makin tinggi; dan (4) idealnya, proporsi jumlah siswa SMA dan SMK didasarkan atas kebutuhan tenaga kerja.
\end{abstract}

Kata kunci: proporsi, konstribusi, pertumbuhan ekonomi, dan pengagguran

\section{THE CONTRIBUTION OF POLICY OF INCREASING THE NUMBER OF VOCATIONAL STUDENTS TO ECONOMIC DEVELOPMENT IN INDONESIA}

\begin{abstract}
To support economic development, The National Education Ministry made significant policy regarding the ratio of general secondary school students to vocational secondary school students from $57.85 \%: 42.15 \%$ in 2007 to $30 \%: 70 \%$ by 2014 , supposedly. It is expected that the policy can support economic growth dan reduce unemployment. This policy change was decided based on assumption only and not based on accurate labor information. The objectives of this study were to find out: (1) proportion of general and vocational school students in 2007 and 2014; (2) the support to economic development from increasing the number of vocational secondary school students in 2007 and 2014; (3) to find out the contribution of increasing the number of vocational school students to unemployment reduction; and (4) the concept of link \& match between vocational school and the world of work in terms of quantity.The research method used to achieve the objectives of research was descriptive quantitative. The research found that: (1) the ratio of general and vocational secondary school students was $51 \%: 49 \%$ in 2014 ; (2) increasing the number of vocational school students did not support economic growth; (3) increasing the number of vocational school students increased unemployment of vocational school graduates; and (4) ideally, proportion of general and vocational students must be based on the needs of labor.
\end{abstract}

Keywords: proportion, contribution, economic growth, and unemployment

\section{PENDAHULUAN}

Dalam urusan politik dan ekonomi pendidikan, Indonesia belum memiliki arah yang jelas. Ke manakah arah politik pendidikan Indonesia? Semestinya, arah politik pendidikan Indonesia adalah menuju jati diri pendidikan yang mengindonesia, yaitu: (1) berbasis pada karakteristik, potensi dan kebutuhan Indonesia; (2) berdasar- kan Pancasila, berpijak pada pilar-pilar UUD 1945, NKRI, dan bhinneka tunggal ika, dan (3) berjati diri budaya Indonesia. Demikian juga, ke manakah arah ekonomi pendidikan Indonesia? Lebih rincinya, jenis satuan pendidikan manakah yang paling baik, menyiapkan peserta didik yang mana, untuk jenis pekerjaan apa, dan dengan kondisi yang seperti apa? 
Pada tahun 2007, Kementerian Pendidikan Nasional membuat keputusan yang sangat signifikan dalam pendidikan menengah. Dikatakan sangat signifikan karena pada tahun tersebut dibuat keputusan besar (big bang policy decision), yaitu pembalikan proporsi jumlah siswa SMK:SMA dari 42,15\%:57,85\% pada tahun 2007 dan diharapkan menjadi 70\%:30\% pada tahun 2014. Kebijakan tersebut kemudian diperkuat melalui penerbitan Peraturan Menteri Pendidikan Nasional Nomor 44 Tahun 2010 tentang Rencana Strategis Kementerian Pendidikan Nasional, yang kemudian dirinci dalam Rencana Strategis Pendidikan Menengah Kejuruan untuk periode tahun 2010-2014, dan diluweskan proporsinya sesuai kespesifikan/konteks daerah melalui Permendikbud Nomor 80 Tahun 2013 tentang Pendidikan Menengah Universal.

Untuk mewujudkan kebijakan tersebut, setiap kebupaten/kota mendirikan SMK baru sesuai arahan dan bantuan Menteri Pendidikan Nasional c.q. Direktorat Pembinaan Sekolah Menengah Kejuruan (Direktorat Pembinaan SMK). Berdasarkan Memorandum of Understanding (MOU) disepakati bersama antara Direktorat Pembinaan SMK dan Pemerintah Kabupaten/Kota, keduanya memiliki kewajiban dan tanggung jawab sebagai berikut. Direktorat Pembinaan SMK membuatkan gedung baru dan pemerintah kabupaten/kota menyediakan lahan, guru dan peralatan/fasilitas pembelajaran. Untuk mendukung ketercapaian proporsi 30\% siswa SMA dan 70\% siswa SMK pada tahun 2014, Direktorat Pembinaan SMK melakukan pemasaran secara besar-besaran melalui iklan diberbagai media cetak dan elektronik (surat kabar, majalah, radio, televisi, dan sebagainya).

Permasalahannya adalah: tepatkah kebijakan tersebut untuk mendukung pembangunan ekonomi Indonesia, khususnya untuk mendukung pertumbuhan ekonomi dan pengurangan pengangguran lulusan SMK? Lebih rincinya, empat pertanyaan berikut harus dijawab melalui penelitian ini, yaitu: (1) Berapakah proporsi jumlah siswa SMK dibanding siswa SMA pada tahun 2007 dan tahun 2014?; (2) Seberapa besar kontribusi ekspansi jumlah siswa SMK terhadap pertumbuhan ekonomi?; (3) Seberapa besar kontribusi ekspansi jumlah siswa SMK terhadap pengurangan pengangguran lulusan SMK?; dan (4) Berapakah idealnya proporsi jumlah siswa SMA:SMK agar mendukung pembangunan ekonomi Indonesia?
Penelitian ini penting dilakukan untuk menjawab empat pertanyaan penelitian tersebut agar penambahan jumlah siswa SMK dimasa depan selaras dengan kebutuhan dunia kerja.

Semua negara mengakui bahwa kemajuan berkelanjutan ditentukan oleh modal-modal yang dimilikinya, yaitu manusia (human), alam (natural/material), budaya (cultural), sosial (social), ideologi (ideological), uang (financial), dan teknologi/man-made capitals (Slamet $\mathrm{PH}$, 2013). Dari semua itu, manusialah yang paling menentukan kemajuan berkelanjutan suatu negara karena manusialah satu-satunya sumber daya aktif dan sumber-sumber daya lainnya pasif (peralatan, perlengkapan, perbekalan, uang, bahan, dan informasi). Hanya manusia pulalah yang memiliki banyak wawasan untuk maju, yaitu wawasan religis, sistemis, filosofis, etis/moralis, estetis, teoris, metodologis, yuridis, sebab-akibat, dan mondial. Manusia pulalah satu-satunya yang memiliki hasrat (keinginan), harkat (kemampuan kodrati cipta, rasa, dan karsa) untuk maju, dan martabat (kedudukan luhur manusia diatas makhlukmakhluk Tuhan lainnya di dunia). Dari ini semua dapat dipetik pelajaran bahwa tinggi rendahnya kualitas warga bangsa suatu negara menjadi barometer bagi kemajuan/perkembangannya .

Pendidikan kejuruan (SMK) diharapkan berperan penting dalam pengembangan manusia seutuhnya dan pembangunan masyarakat Indonesia seluruhnya. Slamet PH $(2011,2013)$ menegaskan bahwa pengembangan manusia seutuhnya mencakup kualitas dasar (daya pikir, daya hati, daya pisik), kualitas instrumental (ilmu, teknologi, seni, dan olah raga selaras dengan karakteristik dan kebutuhan Indonesia), kualitas ke-Indonesia-an, dan kualitas global (lihat Gambar 1). Catatan: istilah pendidikan kejuruan dan sekolah menengah kejuruan/SMK digunakan secara silih berganti).

Kajian teori dan hasil-hasil penelitian tentang kontribusi pendidikan terhadap pembangunan ekonomi telah banyak dilakukan sejak tahun 1960 an yang intinya bahwa investasi di bidang pendidikan berkontribusi lebih besar dalam pembangunan ekonomi daripada investasi di bidang-bidang lainnya (Becker 1964; Psacharopoulous, 1987, 1997). Hasil-hasil penelitian selama ini juga mengukuhkan klaim tersebut. Misalnya, Boediono dan McMahon (2001) menyimpulkan bahwa investasi di bidang pendidikan berkontribusi besar terhadap pembangunan ekonomi di Indonesia. Direktorat 


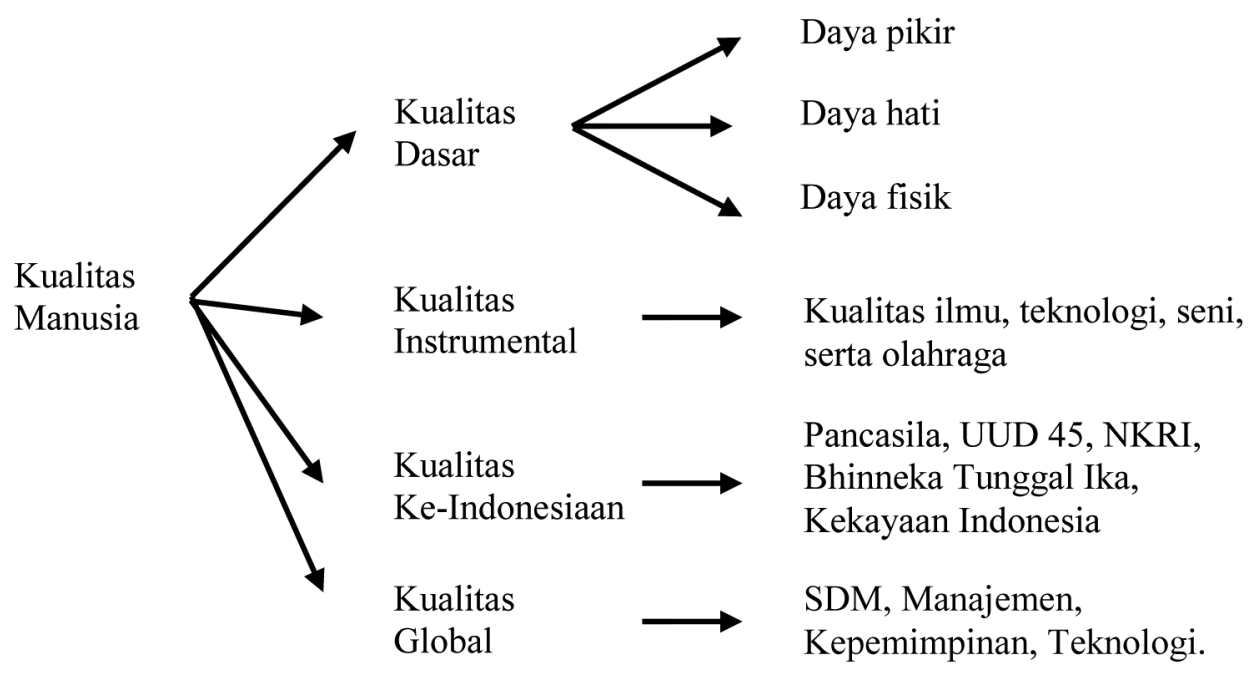

Gambar 1. Dimensi Pengembangan Kualitas Manusia

Pembinaan Sekolah Menengah Kejuruan (2008) dan ADB (2008) melakukan kajian strategi ekspansi SMK yang menyimpulkan bahwa "Agar ekspansi SMK relevan dengan kebutuhan DUDI dan wilayah terkait, maka penambahan siswa dan SMK adalah yang mengedepankan bidang-bidang keahlian yang memiliki daya serap tinggi."

Agar pendidikan kejuruan mampu menyelaraskan diri dengan kebutuhan dunia kerja/ masyarakat, King \& Palmer (2010) berpendapat bahwa abad ke-21 memerlukan reformasi fungsi pendidikan kejuruan. Untuk Indonesia, pendapat mereka bukanlah hal baru karena pada tahun 1998 Direktorat Pembinaan SMK telah melakukan reformasi dengan konsepnya yang disebut Skills Toward 2020 yang intinya bahwa SMK harus berbasis demand driven (berbasis kebutuhan dunia kerja dengan segala variasi jenis-jenisnya). Skills Toward 2020 juga sangat selaras dengan saran UNESCO (1984) bahwa pendidikan kejuruan agar menata ulang organisasi dan koordinasinya dengan dunia kerja.

Persediaan (supply) tenaga kerja di Indonesia dilakukan melalui jalur-jalur pendidikan, pelatihan, dan pengembangan di tempat kerja. Jalur pendidikan ditempuh melalui pendidikan formal (SD, SMP, SMA, SMK, PT), nonformal dan informal (pendidikan anak usia dini, penitipan anak, kelompok bermain, taman kanak-kanak, pendidikan masyarakat). Jalur pelatihan ditempuh melalui balai pelatihan kerja, kursus-kursus keterampilan kejuruan, dan pelatihan oleh lembagalembaga pelatihan selain kedua tersebut. Jalur pengembangan di tempat kerja ditempuh melalui pemagangan/pelatihan di tempat kerja.
Meskipun tidak tersedia data lengkap dan akurat, penyediaan tenaga kerja di Indonesia cenderung monoton dan terkanalisasi pada bidangbidang tertentu. Kelompok-kelompok bidang studi yang dikembangkan di pendidikan kejuruan kurang menyesuaikan dengan tuntutan dunia kerja yang cepat berubah dan sangat beragam. Akibatnya, terjadi oversupply pada bidang-bidang pekerjaan tertentu dan undersupply pada bidangbidang pekerjaan tertentu lainnya.

Tingkat pengangguran disebabkan oleh banyak faktor, antara lain pertumbuhan ekonomi yang rendah, jenis investasi yang padat modal, kebijakan fiskal (jenis belanja dan besar kecilnya pajak), mutu/kualitas pencari kerja rendah, informasi pasar kerja yang kurang akurat atau bahkan belum ada, kebijakan moneter, lemahnya jiwa kewirausahaan para pencari kerja, dan kultur lulusan yang selalu ingin menjadi pekerja dan bukannya ingin menjadi orang yang mempekerjakan pekerja alias wirausahawan/pengusaha. Pengangguran lulusan SMK dapat diperkecil jika keselarasannya dengan kebutuhan dunia kerja makin tinggi dalam dimensi-dimensi jumlah/ kuantitas, kualitas, lokasi, dan waktu (Slamet $\mathrm{PH}, 2011)$.

Permintaan (demand) tenaga kerja berasal dari dunia kerja yang dimensi-dimensinya diukur dengan kuantitas, kualitas, lokasi, dan waktu. Kuantitas menyangkut jumlah tenaga kerja yang dibutuhkan, kualitas menyangkut kualifikasi dan kompetensi yang dibutuhkan oleh dunia kerja, lokasi merujuk kepada tempat dimana pekerjaan dibutuhkan, dan waktu merujuk kepada kapan tenaga kerja dibutuhkan (tahun depan, dua tahun ke depan, lima tahun ke depan, dan seterusnya). 
Permintaan tenaga kerja dapat dikategorikan menjadi: sektor formal dan sektor informal; sektor publik dan swasta; sektor profit dan nonprofit; dan sektor primer, sektor sekunder, sektor tersier serta sektor kuarter. Usaha-usaha profit meliputi misalnya industri, bank, hotel, restoran, dan transportasi. Secara umum, pertumbuhan lapangan kerja untuk masing-masing sektor mengalami perlambatan.

Usaha-usaha nonprofit meliputi misalnya yayasan, pendidikan, pelatihan, dan rumah sakit. Sektor primer meliputi misalnya pertanian, peternakan, kelautan, perikanan, dan kehutanan. Sektor sekunder umumnya meliputi industri manufaktur, misalnya industri mobil, perusahaan sepatu, dan perusahaan televisi. Sektor tersier (jasa langsung) misalnya bank, transportasi, perhotelan, pendidikan, dan pelatihan. Sedang sektor kuarter adalah jasa tidak langsung, misalnya konsultan, dewan pertimbangan, komisaris, dan penasehat.

Masih banyaknya penganggur menunjukkan bahwa tingkat keselarasan penyelenggaraan pendidikan kejuruan dengan kebutuhan dunia kerja masih rendah dan karenanya diperlukan upaya-upaya penyelarasan yang mampu mendekatkan pendidikan kejuruan dengan kebutuhan dunia kerja, misalnya dengan pertumbuhan ekonomi, pertumbuhan kesempatan kerja, dan elastisitas kesempatan kerja.

Intinya, penyelenggaraan pendidikan kejuruan harus selaras dengan kebutuhan dunia kerja dalam dimensi kuantitas, kualitas, lokasi, dan waktu yang diupayakan melalui berbagai cara dimana pengembangan SMK Rujukan merupakan salah satunya (lihat tiga belas fungsi majemuk SMK oleh Slamet PH, 2013).

Pendidikan kejuruan itu utamanya adalah pendidikan ekonomi sehingga tiga pertanyaan berikut harus dijawab dengan tepat, yaitu what to produce, how to produce, and for whom. Oleh karena itu, SMK harus propenciptaan lapangan kerja, prokegiatan ekonomi, propertumbuhan ekonomi, propengurangan pengangguran, propemerataan ekonomi, dan prokesejahteraan (projob, proactivity, progrowth, prodistribution, dan proprosperity). Diharapkan pula bahwa penambahan jumlah siswa SMK mampu memberi kontribusi yang signifikan terhadap peningkatan PDB, pertumbuhan ekonomi, pertumbuhan penciptaan lapangan kerja, pengurangan angka pengangguran, dan pengurangan angka kemiskinan.

Akhir-akhir ini, melalui Instruksi Presiden Republik Indonesia Nomor 9 Tahun 2016 tentang
Revitalisasi Sekolah Menengah Kejuruan dalam Rangka Peningkatan Kualitas dan Daya Saing Sumber Daya Manusia Indonesia, diinstruksikan agar para kabinet kerja, badan nasional sertifikasi profesi, dan para gubernur, melakukan langkahlangkah merevitalisasi SMK, menyusun peta kebutuhan tenaga kerja bagi lulusan SMK, dan diinstruksikan bahwa semua pemangku kepentingan SMK merevitalisasi dirinya agar tugas dan fungsinya mendukung pengembangan SMK.

Agar lulusan SMK lebih kuat dalam mendukung pembangunan ekonomi, rencana pengembangan SMK ke depan harus benar-benar didasarkan atas manpower planning approach, bukan social demand planning approach. Dalam manpower planning approach, tahap-tahap pengembangan perencanaan SMK yang harus ditempuh adalah sebagai berikut: (1) menghitung persediaan tenaga kerja, (2) menghitung permintaan tenaga kerja, (3) mencari kesenjangan antara persediaan dan permintaan tenaga kerja, dan (4) menyusun program berdasarkan hasil nomor 3 .

\section{METODE}

Metode penelitian yang digunakan untuk menjawab pertanyaan penelitian nomor 1,2 , 3, dan 4 adalah metode diskriptif kuantitatif. Metode diskriptif kuantitatif digunakan untuk menghimpun, menabulasi, dan meringkas datadata kuantitatif yang dikumpulkan dari Direktorat Pembinaan SMK, data-data sekunder pembangunan ekonomi yang dikumpulkan dari BPS yaitu pertumbuhan ekonomi dan angka pengangguran lulusan SD, SMP, SMA, dan SMK. Rancangan penelitian diwujudkan dalam bentuk langkahlangkah berikut: persiapan, penyusunan instrumen, pengumpulan data, analisis data sekunder, dan penyusunan laporan. Populasi penelitian ini adalah seluruh SMK yang tersebar di seluruh provinsi di Indonesia. Untuk mencari kontribusi SMK terhadap pertumbuhan ekonomi dan pengurangan angka pengangguran SMK, data sekunder digunakan yang diambil dari BPS dan Direktorat Pembinaan SMK. Untuk menjawab pertanyaan penelitian nomor 1, 2, 3, dan 4 digunakan analisis data deskriptif kuantitatif.

Untuk menjawab pertanyaan penelitian nomor 1, data jumlah siswa SMK dan SMA dikumpulkan dari Kementerian Pendidikan dan Kebudayaan cq. Direktorat Pembinaan SMK (Tabel 1) dan Direktorat Pembinaan SMA (Tabel 2), kemudian dianalisis yang hasilnya berupa proporsi jumlah siswa SMK dibanding 
jumlah siswa SMA (Tabel 3). Untuk menjawab pertanyaan penelitian nomor 2, yaitu kontribusi ekspansi jumlah siswa SMK terhadap pertumbuhan ekonomi, datanya dikumpulkan dari BPS. Untuk menjawab pertanyaan penelitian nomor
3, yaitu kontribusi ekspansi jumlah siswa SMK terhadap pengurangan pengangguran lulusan SD, SMP, SMA, dan SMK, datanya diambil dari BPS. Untuk menjawab pertanyaan penelitian nomor 4, yaitu proporsi jumlah siswa SMK:SMA yang

Tabel 1. Jumlah Siswa SMK 2012-2014

\begin{tabular}{|c|c|c|c|c|}
\hline \multirow{2}{*}{ No. } & \multirow{2}{*}{ Provinsi } & \multicolumn{3}{|c|}{ Tahun } \\
\hline & & 2012 & 2013 & 2014 \\
\hline 1. & Aceh & 47,474 & 49,147 & 49,266 \\
\hline 2. & Sumatera Utara & 319,618 & 325,588 & 341,406 \\
\hline 3. & Sumatera Barat & 82,289 & 83,881 & 86,095 \\
\hline 4. & Riau & 70,406 & 79,236 & 79,425 \\
\hline 5. & Jambi & 39,057 & 39757 & 40854 \\
\hline 6. & Sumatera Selatan & 81,897 & 90,440 & 91,164 \\
\hline 7. & Bengkulu & 25,456 & 26473 & 25533 \\
\hline 8. & Lampung & 109,736 & 112,146 & 108,405 \\
\hline 9. & Kepulauan Bangka Belitung & 20305 & 19995 & 20536 \\
\hline 10. & Kepulauan Riau & 19814 & 21399 & 21951 \\
\hline 11. & DKI Jakarta & 235,587 & 226,294 & 235,857 \\
\hline 12. & Jawa Barat & 717,362 & 770,982 & 748,265 \\
\hline 13. & Jawa Tengah & 616,910 & 641,129 & 618,640 \\
\hline 14. & DI Yogyakarta & 84,642 & 83,409 & 85,114 \\
\hline 15. & Jawa Timur & 662,926 & 670,865 & 698,550 \\
\hline 16. & Banten & 180,664 & 192,821 & 187,279 \\
\hline 17. & Bali & 70,447 & 78,619 & 79,815 \\
\hline 18. & Nusa Tenggara Barat & 52,493 & 48,261 & 48,380 \\
\hline 19. & Nusa Tenggara Timur & 56,632 & 75058 & 74,236 \\
\hline 20. & Kalimantan Barat & 49095 & 51420 & 51543 \\
\hline 21. & Kalimantan Tengah & 22740 & 23,591 & 23,648 \\
\hline 22. & Kalimantan Selatan & 37,745 & 40,128 & 40,927 \\
\hline 23. & Kalimantan Timur & 70,878 & 66,981 & 69,647 \\
\hline 24. & Kalimantan Utara ${ }^{1}$ & 0 & 0 & 0 \\
\hline 25. & Sulawesi Utara & 48,554 & 54,254 & 54,382 \\
\hline 26. & Sulawesi Tengah & 30,801 & 36,120 & 36,206 \\
\hline 27. & Sulawesi Selatan & 127,561 & 134,453 & 134,777 \\
\hline 28. & Sulawesi Tenggara & 25,216 & 27,265 & 27,330 \\
\hline 29. & Gorontalo & 18003 & 18866 & 18912 \\
\hline 30. & Sulawesi Barat & 21206 & 24906 & 24967 \\
\hline 31. & Maluku & 18110 & 18464 & 18509 \\
\hline 32. & Maluku Utara & 14757 & 15732 & 15769 \\
\hline 33. & Papua Barat & 14504 & 13765 & 14127 \\
\hline & Papua & 26272 & 28074 & 28142 \\
\hline & Indonesia & $4,019,157$ & $4,189,519$ & $4,199,657$ \\
\hline
\end{tabular}

Sumber: Kemendikbud, 2015 
selaras dengan kebutuhan pembangunan ekonomi Indonesia, khususnya untuk mendukung pertumbuhan ekonomi dan pengurangan pengangguran, datanya diambil dari Kementerian Pendidikan dan
Kebudayaan dan Badan Pusat Statistik. Semua data yang dikumpulkan adalah data sekunder yang berasal dari sumber data yang telah disebut.

Tabel 2. Jumlah Siswa SMA 2012-2014

\begin{tabular}{|c|c|c|c|c|}
\hline \multirow{2}{*}{ No. } & \multirow{2}{*}{ Provinsi } & \multicolumn{3}{|c|}{ Tahun } \\
\hline & & 2012 & 2013 & 2014 \\
\hline 1. & Aceh & 155268 & 157,995 & 154,135 \\
\hline 2. & Sumatera Utara & 344301 & 346,919 & 344,754 \\
\hline 3. & Sumatera Barat & 128789 & 132,449 & 131,698 \\
\hline 4. & Riau & 115547 & 118,171 & 119,252 \\
\hline 5. & Jambi & 66681 & 70757 & 67737 \\
\hline 6. & Sumatera Selatan & 191407 & 200,078 & 202,054 \\
\hline 7. & Bengkulu & 44346 & 45962 & 48294 \\
\hline 8. & Lampung & 121345 & 123,072 & 126,141 \\
\hline 9. & Kepulauan Bangka Belitung & 20560 & 21107 & 21424 \\
\hline 10. & Kepulauan Riau & 28027 & 33621 & 34663 \\
\hline 11. & DKI Jakarta & 187656 & 188,696 & 183,575 \\
\hline 12. & Jawa Barat & 566086 & 567,233 & 568,479 \\
\hline 13. & Jawa Tengah & 400184 & 403,375 & 400,583 \\
\hline 14. & DI Yogyakarta & 51591 & 53,099 & 53,125 \\
\hline 15. & Jawa Timur & 494472 & 495,558 & 493,873 \\
\hline 16. & Banten & 148069 & 153,169 & 156,938 \\
\hline 17. & Bali & 80374 & 80,621 & 83,810 \\
\hline 18. & Nusa Tenggara Barat & 98556 & 100,548 & 99,465 \\
\hline 19. & Nusa Tenggara Timur & 119906 & 123043 & 128,553 \\
\hline 20. & Kalimantan Barat & 93365 & 94892 & 98180 \\
\hline 21. & Kalimantan Tengah & 47903 & 48,283 & 47,524 \\
\hline 22. & Kalimantan Selatan & 51678 & 54,657 & 55,579 \\
\hline 23. & Kalimantan Timur & 68693 & 73,521 & 73,588 \\
\hline 24. & Kalimantan Utara ${ }^{1}$ & 0 & 0 & 0 \\
\hline 25. & Sulawesi Utara & 51252 & 51,524 & 52,199 \\
\hline 26. & Sulawesi Tengah & 56921 & 57,645 & 58,062 \\
\hline 27. & Sulawesi Selatan & 185474 & 188,995 & 200,021 \\
\hline 28. & Sulawesi Tenggara & 76940 & 79,787 & 77,231 \\
\hline 29. & Gorontalo & 19796 & 20692 & 19625 \\
\hline 30. & Sulawesi Barat & 21709 & 22899 & 22897 \\
\hline 31. & Maluku & 61205 & 62305 & 62513 \\
\hline 32. & Maluku Utara & 30168 & 31597 & 34008 \\
\hline 33. & Papua Barat & 22802 & 23842 & 23380 \\
\hline 34. & Papua & 45396 & 46748 & 48928 \\
\hline & Indonesia & $4,196,467$ & $4,272,860$ & $4,292,288$ \\
\hline
\end{tabular}

Sumber: Kemendikbud, 2015 


\section{HASIL DAN PEMBAHASAN}

\section{Hasil}

Hasil penelitian diurutkan berdasarkan pertanyaan penelitian nomor 1, 2, 3, dan 4 yang harus dijawab.
Proporsi Jumlah Siswa SMK dibanding Siswa SMA

Tabel 1 berikut adalah data jumlah siswa SMK untuk tahun 2012, 2013, dan 2014.

Tabel 3. Proporsi Jumlah Siswa SMK:SMA untuk Tahun 2012- 2014

\begin{tabular}{|c|c|c|c|c|c|c|c|c|c|c|}
\hline \multirow{3}{*}{ No. } & \multirow{3}{*}{ Provinsi } & \multicolumn{3}{|c|}{2012} & \multicolumn{3}{|c|}{2013} & \multicolumn{3}{|c|}{2014} \\
\hline & & \multicolumn{3}{|c|}{ Perbandingan } & \multicolumn{3}{|c|}{ Perbandingan } & \multicolumn{3}{|c|}{ Perbandingan } \\
\hline & & SMK & 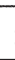 & SMA & SMK & : & SMA & SMK & : & SMA \\
\hline 1. & Aceh & 1 & 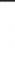 & 3.271 & 1 & : & 3.215 & 1 & : & 3.129 \\
\hline 2. & Sumatera Utara & 1 & & 1.077 & 1 & : & 1.066 & 1 & : & 1.010 \\
\hline 3. & Sumatera Barat & 1 & & 1.565 & 1 & : & 1.579 & 1 & : & 1.530 \\
\hline 4. & Riau & 1 & & 1.641 & 1 & : & 1.491 & 1 & : & 1.501 \\
\hline 5. & Jambi & 1 & & 1.707 & 1 & : & 1.780 & 1 & : & 1.658 \\
\hline 6. & Sumatera Selatan & 1 & & 2.337 & 1 & : & 2.212 & 1 & : & 2.216 \\
\hline 7. & Bengkulu & 1 & & 1.742 & 1 & : & 1.736 & 1 & : & 1.891 \\
\hline 8. & Lampung & 1 & & 1.106 & 1 & : & 1.097 & 1 & : & 1.164 \\
\hline 9. & Kepulauan Bangka Belitung & 1 & & 1.013 & 1 & : & 1.056 & 1 & : & 1.043 \\
\hline 10. & Kepulauan Riau & 1 & & 1.415 & 1 & : & 1.571 & 1 & : & 1.579 \\
\hline 11. & DKI Jakarta & 1 & & 0.797 & 1 & : & 0.834 & 1 & : & 0.778 \\
\hline 12. & Jawa Barat & 1 & & 0.789 & 1 & : & 0.736 & 1 & : & 0.760 \\
\hline 13. & Jawa Tengah & 1 & & 0.649 & 1 & : & 0.629 & 1 & : & 0.648 \\
\hline 14. & DI Yogyakarta & 1 & & 0.610 & 1 & : & 0.637 & 1 & : & 0.624 \\
\hline 15. & Jawa Timur & 1 & & 0.746 & 1 & : & 0.739 & 1 & : & 0.707 \\
\hline 16. & Banten & 1 & & 0.820 & 1 & : & 0.794 & 1 & : & 0.838 \\
\hline 17. & Bali & 1 & & 1.141 & 1 & : & 1.025 & 1 & : & 1.050 \\
\hline 18. & Nusa Tenggara Barat & 1 & & 1.878 & 1 & : & 2.083 & 1 & : & 2.056 \\
\hline 19. & Nusa Tenggara Timur & 1 & & 2.117 & 1 & : & 1.639 & 1 & : & 1.732 \\
\hline 20. & Kalimantan Barat & 1 & & 1.902 & 1 & : & 1.845 & 1 & : & 1.905 \\
\hline 21. & Kalimantan Tengah & 1 & & 2.107 & 1 & : & 2.047 & 1 & : & 2.010 \\
\hline 22. & Kalimantan Selatan & 1 & & 1.369 & 1 & : & 1.362 & 1 & : & 1.358 \\
\hline 23. & Kalimantan Timur & 1 & & 0.969 & 1 & : & 1.098 & 1 & : & 1.057 \\
\hline 24. & Kalimantan Utara ${ }^{1}$ & & & & & & & & & \\
\hline 25. & Sulawesi Utara & 1 & & 1.056 & 1 & ? & 0.950 & 1 & : & 0.960 \\
\hline 26. & Sulawesi Tengah & 1 & & 1.848 & 1 & : & 1.596 & 1 & : & 1.604 \\
\hline 27. & Sulawesi Selatan & 1 & & 1.454 & 1 & : & 1.406 & 1 & : & 1.484 \\
\hline 28. & Sulawesi Tenggara & 1 & & 3.051 & 1 & : & 2.926 & 1 & : & 2.826 \\
\hline 29. & Gorontalo & 1 & & 1.100 & 1 & : & 1.097 & 1 & : & 1.038 \\
\hline 30. & Sulawesi Barat & 1 & & 1.024 & 1 & : & 0.919 & 1 & : & 0.917 \\
\hline 31. & Maluku & 1 & & 3.380 & 1 & ? & 3.374 & 1 & : & 3.377 \\
\hline 32. & Maluku Utara & 1 & & 2.044 & 1 & : & 2.008 & 1 & : & 2.157 \\
\hline 33. & Papua Barat & 1 & & 1.572 & 1 & : & 1.732 & 1 & : & 1.655 \\
\hline 34. & Papua & 1 & & 1.728 & 1 & I & 1.665 & 1 & : & 1.739 \\
\hline & Indonesia & 1 & & 1.044 & 1 & & 1.020 & 1 & : & 1.022 \\
\hline
\end{tabular}

Sumber: Diolah dari Data Kemendikbud, 2015 
Berdasarkan perhitungan dari Tabel 1 dan Tabel 2 ditemukan bahwa secara nasional (agregat) proporsi jumlah siswa SMK:SMA pada tahun 2014 adalah 1:1,022 (49\%:51\%), dan secara disagregat (setiap provinsi) dapat dilihat pada Tabel 3. Dibanding data proporsi jumlah siswa SMK:SMA pada tahun 2007 yaitu 42,15\% : $57,85 \%$, maka dapat disimpulkan bahwa kenaikan jumlah siswa SMK sangat signifikan.

\section{Kontribusi Ekspansi Jumlah Siswa SMK ter- hadap Pertumbuhan Ekonomi}

Angka pertumbuhan ekonomi dipengaruhi oleh banyak faktor, misalnya investasi, konsumsi, dan kualitas tenaga kerja. Yang terakhir ini jarang diperhitungkan, padahal semuanya tahu bahwa tenaga kerja merupakan satu-satunya sumber daya aktif. Oleh karena itu, seberapa besar kontribusi ekspansi jumlah siswa SMK terhadap pertumbuhan ekonomi nasional (agregat) dan setiap propinsi (disagregat) harus diperhitungkan, tetapi sangat rumit perhitungannya dan belum dianalisis dalam penelitian ini. Namun, kontribusi ekspansi jumlah siswa SMK terhadap angka pertumbuhan ekonomi, setidaknya dapat dibaca dari sinyal-sinyal awal dari hubungan antara pertambahan jumlah siswa SMK dan angka pertumbuhan ekonomi.

Berdasarkan data jumlah siswa SMK pada tahun 2007 dan tahun 2014, terbaca bahwa pertumbuhan jumlah siswa SMK sangat signifikan yaitu dari $42,15 \%$ pada tahun 2007 menjadi $57,85 \%$ pada tahun 2014. Sementara itu, pertumbuhan ekonomi sebesar 6,35\% pada tahun 2007 dan 5,06\% pada tahun 2014. Peningkatan jumlah siswa SMK tidak sejalan dengan peningkatan angka pertumbuhan ekonomi yang hanya 5,06\% dan bahkan sebaliknya. Ini berarti bahwa penambahan jumlah siswa SMK tidak mendukung pertumbuhan ekonomi nasional. Simplikasi ini memang terlalu menyederhanakan banyaknya variabel yang berpengaruh terhadap angka pertumbuhan ekonomi, tetapi temuan awal yang bersifat eksploratif ini dapat ditindaklanjuti melalui eksplanasi yang dilakukan melalui analisis structural equation modeling (SEM).

\section{Kontribusi Ekspansi Jumlah Siswa SMK ter- hadap Pengurangan Pengangguran}

Tingkat pengangguran disebabkan oleh banyak faktor, antara lain pertumbuhan ekonomi, jenis investasi (padat karya/modal), kebijakan fiskal (jenis belanja dan besar kecilnya pajak), mutu/kualitas pencari kerja, kejelasan informasi pasar kerja, kebijakan moneter, tinggi rendahnya jiwa kewirausahaan para pencari kerja, dan kultur lulusan (banyak yang ingin menjadi pekerja dan bukannya ingin menjadi orang yang mempekerjakan pekerja alias wirausahawan/pengusaha). Oleh karena itu, penambahan jumlah siswa SMK bukanlah satu-satunya variabel yang berpengaruh terhadap tingkat pengangguran.

Data tingkat pengangguran pada Tabel 4 berikut menunjukkan bahwa tingkat pengangguran lulusan SMK makin banyak dengan bertambahnya jumlah siswa SMK. Ini memberi sinyal bahwa penambahan jumlah siswa SMK malah meningkatkan pengangguran lulusannya. Kontribusi ekspansi jumlah siswa SMK terhadap pengurangan pengangguran tidak berkorelasi positif. Tingkat pengangguran lulusan SMK justru bertambah dengan bertambahnya persentase jumlah siswa SMK. Ini jelas tidak efisien karena SMK memiliki tugas dan fungsi pokok menyiapkan lulusannya untuk bekerja dan biaya penyelenggaraanyapun jauh lebih mahal dari pada SMA. Oleh karena itu, untuk sementara waktu, ekspansi jumlah siswa SMK harus dihentikan.

Tabel 4. Tingkat Pengangguran Berdasarkan Tingkat Pendidikan 2012-2015

\begin{tabular}{llcccc}
\hline No. & $\begin{array}{l}\text { Pendidikan Tertinggi yang } \\
\text { ditamatkan }\end{array}$ & $\begin{array}{c}2012 \\
\%\end{array}$ & $\begin{array}{c}2013 \\
\%\end{array}$ & $\begin{array}{c}2014 \\
\%\end{array}$ & $\begin{array}{c}2015 \\
\%\end{array}$ \\
\hline 1. & SD ke bawah & 3,69 & 3,44 & 3,04 & 2,74 \\
2. & SMP & 7,80 & 7,59 & 7,15 & 6,22 \\
3. & SMA & 10,34 & 9,72 & 9,55 & 10,32 \\
4. & SMK & $\mathbf{9 , 5 1}$ & $\mathbf{1 1 , 2 1}$ & $\mathbf{1 1 , 2 4}$ & $\mathbf{1 2 , 6 5}$ \\
5. & Diploma I/II/III & 7,50 & 5,95 & 6,14 & 7,54 \\
6. & Universitas & 6,95 & 5,39 & 5,65 & 6,40
\end{tabular}

Sumber: bps.go.id, diakses 15 April 2016 
Proporsi Ideal Jumlah Siswa SMK:SMA untuk Mendukung Pembangunan Ekonomi Indonesia

Penelitian ini belum bisa menjawab pertanyaan penelitian nomor 4, yaitu berapa proporsi ideal jumlah siswa SMK:SMA untuk mendukung pembangunan ekonomi Indonesia. Tetapi, temuan penelitian ini sudah memberi sinyal bahwa makin diperbanyak siswa SMK, makin besar pula tingkat pengangguran lulusannya. Untuk menjawab pertanyaan penelitian tersebut, pada tahun 2017 akan dilakukan penelitian lanjutan atas bantuan dana dari IDB Project.

Sebagai rancangan tahun 2017, untuk menentukan proporsi ideal jumlah siswa SMK:SMA agar mendukung pembangunan ekonomi Indonesia, akan diteliti tentang data-data persediaan dan permintaan tenaga kerja secara nasional (agregat) dan per propinsi (disagregat), sistem informasi pasar kerja yang mutakhir, akurat, dan keberlanjutan, yang mencakup informasi persediaan dan permintaan tenaga kerja secara nasional dan per propinsi. Dari hasil pengumpulan data tersebut, nantinya juga akan dikembangkan SMK Rujukan yang mampu mendukung pembangunan ekonomi Indonesia. Penelitian yang akan dilakukan pada tahun 2017 menggunakan data kuantitatif dan kualitatif.

\section{Pembahasan}

Pembahasan hasil penelitian berikut berdasarkan temuan penelitian yang diurutkan sebagai berikut. Pertama, terkait dengan hasil penelitian nomor 1 yaitu proporsi jumlah siswa SMK dibanding siswa SMA, ditemukan bahwa kenaikan jumlah siswa SMK sangat signifikan. Mengingat esensi pendidikan kejuruan adalah keselarasannya dengan dunia kerja (Slamet PH, 2011; 2013; 2014; dan 2015), maka penambahan jumlah siswa SMK harus dikendalikan agar selaras dengan kebutuhan dunia kerja. Keselarasan antara persediaan dan permintaan tenaga kerja harus equilibrium agar efisiensi pendidikan dapat dijaga.

Kedua, temuan penelitian nomor 2 disimpulkan bahwa peningkatan jumlah siswa SMK tidak mendukung peningkatan angka pertumbuhan ekonomi dan bahkan sebaliknya. Hasil penelitian ini sesuai dengan hasil penelitian Boediono \& McMahon (2001) yang menyimpulkan bahwa investasi di SMK tidak lebih efisien daripada investasi di SD, SMP, SMA, dan PT karena nilai baliknya (rate of return) nya paling rendah. Temuan penelitian ini juga bertolak belakang dengan human capital theory yang dikembangkan oleh Becker (1964) karena penambahan jumlah siswa SMK ternyata tidak mendukung pertumbuhan ekonomi, padahal SMK seharusnya merupakan investasi pembangunan ekonomi.

Ketiga, ekspansi kuantitas/jumlah siswa SMK tidak berkontribusi terhadap pengurangan pengangguran, bahkan sebaliknya. Makin banyak jumlah siswa SMK, makin banyak pula pengangguran yang berasal dari lulusan SMK. Padahal, pada tahun 2010, Kementerian Pendidikan Nasional bekerja sama dengan Kementerian Tenaga Kerja dan Transmigrasi menerbitkan Kerangka Kerja Penyelarasan Pendidikan dengan Dunia Kerja sebagai pedoman pengembangan SMK. Dalam praksisnya, kerangka kerja tersebut tidak dilaksanakan secara konsisten.

Keempat, proporsi ideal jumlah siswa SMK:SMA untuk mendukung pembangunan ekonomi Indonesia baru akan dilaksanakan pada tahun 2017. Selain itu, secara kualitatif, konsep SMK Rujukan juga akan diteliti dan dikembangkan pada tahun 2017. Oleh karena itu, konsep proporsi ideal jumlah siswa SMK:SMA dan pengembangan SMK Rujukan harus mengacu pada konsep keselarasan (link \& match) antara dunia pendidikan kejuruan (SMK) dan dunia kerja, baik secara kuantitatif, kualitatif, lokasi, maupun waktu, dan untuk sektor primer, sekunder, tersier, dan kuarter.

\section{PENUTUP}

Hasil penelitian menemukan bahwa: (1) proporsi jumlah siswa SMA:SMK pada tahun 2014 adalah 51\%:49\%; (2) peningkatan jumlah siswa SMK tidak mendukung angka pertumbuhan ekonomi; (3) peningkatan jumlah siswa SMK menyebabkan tingkat pengangguran lulusan SMK makin tinggi; dan (4) idealnya, proporsi jumlah siswa SMA dan SMK harus didasarkan atas kebutuhan tenaga kerja. Temuan ini memberi sinyal bahwa penambahan jumlah siswa SMK harus dilakukan berdasarkan data-data kebutuhan tenaga kerja lulusan SMK yang digali dari dunia kerja. Penguatan keselarasan pendidikan kejuruan dan dunia kerja harus dilakukan secara berkelanjutan melalui survei, perbaikan sistem informasi pasar kerja, dan segera dibentuk suatu badan atau majelis atau apa pun namanya, yang berfungsi mempererat keselarasan (link \& match) SMK dan dunia kerja. Instruksi Presiden Nomor 9 Tahun 2016 tentang Revitalisasi Pendidikan 
Vokasi belum kuat dan harus dijadikan Peraturan Pemerintah atau bahkan Undang-Undang seperti di Jerman.

\section{UCAPAN TERIMA KASIH}

Penulis mengucapkan terima kasih sebanyak-banyaknya kepada para pihak yang telah membantu dan memfasilitasi penelitian ini, terutama para staf dari Direktorat Pembinaan SMK dan Direktorat Pembinaan SMA Kementerian Pendidikan dan Kebudayaan, BPS Jakarta (nasional), BPS Provinsi Lampung, Papua, dan Kalimantan Timur, atas bantuan datanya. Atas kebaikannya, semoga dilipatgandakan balasannya oleh Tuhan Yang Maha Esa.

\section{DAFTAR PUSTAKA}

Asian Development Bank. 2009. Good Practice in Technical and Vocational Education and Training. Manila, The Philippines: Asian Development Bank.

Badan Pusat Statistik. 2016. Data Pertumbuhan Ekonomi Idonesia. Jakarta: Badan Pusat Statistik.

Badan Pusat Statistik. 2016. Data Tingkat Pengangguran Indonesia. Jakarta: Badan Pusat Statistik.

Becker, G.S. 1964. Human Capital. New York, NY.: National Bureau of Economic Research.

Boediono \& McMahon. 2001. Pembangunan Pendidikan untuk Mendukung Pertumbuhan Ekonomi. Jakarta: Badan Penelitian dan Pengembangan, Departemen Pendidikan dan Kebudayaan.

Direktorat Pembinaan SMK. 2010. Rencana Strategis Pendidikan Menengah Kejuruan untuk periode tahun 2010-2014. Jakarta: Kementerian Pendidikan Nasional.

Direktorat Pembinaan SMK. 1998. Skill Toward 2020. Jakarta: Direktorat Pembinaan SMK, Departemen Pendidikan dan Kebudayaan.

Direktorat Pembinaan SMK. 2008. Peran SMK dalam Mendukung Pertumbuhan Ekonomi
Daerah. Jakarta: Direktorat Pembinaan SMK, Departemen Pendidikan Nasional.

Instruksi Presiden Republik Indonesia Nomor 9 Tahun 2016 tentang Revitalisasi Sekolah Menengah Kejuruan dalam Rangka Peningkatan Kualitas dan Daya Saing Sumber Daya Manusia Indonesia.

Kementerian Pendidikan dan Kebudayaan. 2015. Statistik SMA dan SMK. Jakarta: Kementerian Pendidikan dan Kebudayaan.

Kementerian Pendidikan dan Kebudayaan. 2013. Peraturan Menteri Pendidikan dan Kebudayaan Nomor 80 Tahun 2013 tentang Pendidikan Menengah Universal.

Kementerian Pendidikan Nasional dan Kementerian Tenaga Kerja dan Transmigrasi. 2010. Kerangka Kerja Penyelarasan Pendidikan dengan Dunia Kerja. Jakarta: Kementerian Pendidikan Nasional.

Kementerian Pendidikan dan Kebudayaan. 2010. Rencana Strategis (Renstra) Kementerian Pendidikan Nasional 2010-2014. Jakarta: Kementerian Pendidikan dan Kebudayaan.

King, Kenneth \& Robert Palmer.2010. Planning for Technical and Vocational Skills Development. Paris: UNESCO (United Nations Educational, Scientific and Cultural Organization).

Psacharopoulous, G. 1997. "Vocational Education and Training Today: Challenges and Responses", Journal of Vocational Education and Training, 49 (3), h.385-393.

Psacharopoulous, G. 1987. “To vocationalize or Not to Vocationalize: That is the Curriculum Question", Internationale Review of Education, 33 (2), h.187-211.

Slamet PH. 2015. Penyelarasan Pendidikan Kejuruan dengan Dunia Kerja. Jakarta: Direktorat Pembinaan Sekolah Menengah Kejurun, Kementerian Pendidikan dan Kebudayaan. 
Slamet PH. 2014. Pengembangan SMK Model untuk Masa Depan. Jakarta: Direktorat Pembinaan Sekolah Menengah Kejurun, Kementerian Pendidikan dan Kebudayaan.

Slamet PH. 2013. Pengembangan SMK Model untuk Masa Depan (Cakrawala Pendidikan: Jurnal Ilmiah Pendidikan, Februari 2013, Th XXXII, No.1). Yogyakarta: Universitas Negeri Yogyakarta.

Slamet PH. 2013. Pengembangan SMK Selaras Dengan Pelaksanaan Master Plan Percepatan Pembangunan Ekonomi Indonesia (MP3EI). Jakarta: Kementerian Koordinator Bidang Kesejahteraan Rakyat.
Slamet PH. 2011. Peran Pendidikan Vokasi dalam Pembangunan Ekonomi (Cakrawala Pendidikan: Jurnal Ilmiah Pendidikan, Juni 2011, Th XXX, No.2). Yogyakarta: Universitas Negeri Yogyakarta.

Trilling, Bernie \& Charles Fadel.2010. 21 $1^{\text {st }}$ Century Skills: Learning for Life in Our Times. San Francisco, CA: John Wiley \& Sons, Inc.

UNESCO.1992. New Directions in Technical and Vocational Education. Bangkok: UNESCO Principal Regional Office for Asia and the Pacific. 